\title{
LITERATURA E MULTILETRAMENTOS: ALIAYDO O VERBAL E O VISUAL
}

\author{
LITERATURE AND MULTILETERACIES: \\ COMBINING THE VERBAL AND THE VISUAL
}

\author{
Daniely Moreira Coelho da Silva ${ }^{1}$ \\ Maria do Socorro Silva de Aragão ${ }^{2}$ \\ Maria Silvana Militão de Alencar ${ }^{3}$

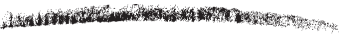

\begin{abstract}
RESUMO
Diante de um mundo tão globalizado, que exige novos padrões de comportamento, em situações diversas de comunicação e de uso da linguagem, propor uma educação, especificamente, no ensino de literatura comprometida com a prática de letramento literário nas aulas de Língua Portuguesa, entrelaçando-a à luz da pedagogia dos multiletramentos, é um dos grandes desafios do professor do Ensino Fundamental, anos finais. Com isso, o presente artigo tem como objetivo promover o letramento literário na perspectiva da pedagogia dos multiletramentos, buscando destacar as semioses na constituição de sentido do texto. Adotamos como metodologia a pesquisa-ação com abordagem qualitativa. Como sugestões de atividades, utilizamos a sequência básica e o diário de leituras. Para embasamento teórico, apropriamo-nos das concepções de Cosson (2018a, 2018b), Machado (2005), Buzzo (2003), Rojo e Moura (2012), Kress e Van Leeuwen (1996, 2006), dentre

\footnotetext{
${ }^{1}$ Doutoranda do Programa de Pós- Graduação em Linguística Aplicada - PosLA da Universidade Estadual do Ceará, Mestre (2019) em linguística pela Universidade Federal do Ceará (Profletras), Especialista (2013) em Administração Escolar (UVA), Graduada (2007) em Letras Português-Francês (UECE). E-mail: daniely.silva@aluno.uece.br. Bolsista da CAPES em 2019. ORCID https://orcid.org/0000-0002-8819-5951

2 Pós-Doutorado na Université de Paris Sorbonne Nouvelle (1976-1977), Pós-Doutorado na Universidad Complutense de Madrid (1976/1978), Pós-Doutorado na Central Connecticut State University - USA (1989/1990), Doutorado em Linguística pela Universidade de São Paulo (1974), Mestrado em Linguística pela Universidade de São Paulo (1973) e Graduação em Letras Anglo Germânicas pela Universidade Regional do Nordeste (1969). E-mail: socorro.aragao@terra.com.br ORCID https://orcid. org/0000-0002-8079-6058

${ }^{3}$ Doutorado em Linguística (2007) pela Universidade Federal do Ceará, Mestrado em Linguística e Ensino da Língua Portuguesa (1997) - UFC, Especialização em Teoria da Linguagem (1979) - UNIFOR, Graduação em Letras pela Universidade Federal do Ceará (1976). E-mail: msmilitão@gmail.com ORCID https://orcid.org/0000-0002-8976-9793. O recorte desse trabalho insere-se numa pesquisa de mestrado intitulada: PRÁTICAS DE LETRAMENTO LITERÁRIO EM UMA TURMA DE 7o ANO, vinculada ao Programa Profissional de Mestrado (PROFLETRAS), da Turma V, na Universidade Federal do Ceará - UFC. Pesquisa financiada pela CAPES.
} 
outros autores. Este trabalho foi aplicado em uma turma do Ensino Fundamental, anos finais, em sala de aula de $7^{\circ}$ ano, na Rede Pública de Ensino de Fortaleza. No processo de leitura literária, o recurso semiótico potencializou a ressignificação do texto literário por parte do leitor.

Palavras-chave: Ensino da Literatura. Letramento literário. Multiletramentos.

\section{ABSTRACT}

In the face of such a globalized world, which requires new patterns of behavior, in different situations of communication and use of language, to propose an education, specifically, in the teaching of literature committed to the practice of literary literacy in Portuguese language classes, intertwining in the light of the multiliteracy pedagogy, it is one of the great challenges of the elementary school teacher, final years. Thus, the present article aims to promote literary literacy from the perspective of multiliteracy pedagogy, seeking to highlight semiosis in the constitution of the text's meaning. We adopted action-research as a methodology with a qualitative approach. As suggested activities, we used the basic sequence and the reading diary. For theoretical support, we used the concepts of Cosson (2018a, 2018b), Machado (2005), Buzzo (2003), Rojo and Moura (2012), Kress and Van Leeuwen (1996, 2006), among other authors. This work was applied to an elementary school class, final years, in a 7th grade classroom, in the Public Education Network of Fortaleza. In the process of literary reading, the semiotic resource enhanced the reframing of the literary text by the reader.

Keywords: Teaching Literature. Literary literacy. Multiliteracies.

\section{INTRODUÇÃO}

O ensino de literatura comprometido com a prática de leitura literária, na busca de promover o letramento literário nas aulas de Língua Portuguesa no Ensino Fundamental, vem sendo um dos grandes desafios para o professor, especialmente em tempos de globalização, já que nesse contexto de leitura, tem-se percebido um espaço diversificado de diferentes semioses que contribuem para a constituição de sentido do texto, exigindo, assim, atividades que dialoguem com a pedagogia dos multiletramentos.

Isso pressupõe uma reflexão quanto ao ensino da literatura, uma vez que se buscam novos padrões de comportamento diante de uma sociedade em constante transformação social que requer, cada vez mais, cidadãos reflexivos, capazes de compreender o mundo em situações sociais diversas.

Compreendemos que a literatura se constitui como uma área de conhecimento grandiosa para o processo de letramento literário e, assim, para a formação de leitores letrados. Nessa perspectiva, precisamos entender a realidade da educação e pensar em novas posturas, levando em consideração as possibilidades dos multiletramentos.

Com isso, o presente artigo tem como objetivo sugerir orientações de como promover práticas de letramento literário, por meio da obra O Gralha, menino de rua, na perspectiva da pedagogia dos multiletramentos, buscando destacar as semioses que são constituintes para a compreensão do texto. 
Adotamos como metodologia, a pesquisa-ação com abordagem qualitativa (THIOLLENT, 1996). Como sugestões de atividades, utilizamos a sequência básica, o círculo de leituras e o diário de leituras. Este trabalho representa um recorte de uma pesquisa de mestrado defendida em 2019. Ele foi aplicado em uma turma do Ensino Fundamental, anos finais, em sala de aula de $7^{\circ}$ ano, na Rede Pública de Ensino de Fortaleza.

Nessa perspectiva, esta pesquisa justifica-se pela relevância da temática para a formação de sujeitos letrados e críticos, pois compreendemos a literatura como um bem cultural e de transformação do indivíduo.

Entendemos que a prática da leitura literária, unindo aspectos da linguagem verbal e visual, para a promoção do letramento literário, proporciona aos educandos experiências de interação, na constituição de significado do texto, o que favorece a formação de sujeitos reflexivos e participativos.

\section{LITERATURA NA ESCOLA RUMO AO LETRAMENTO LITERÁRIO}

De acordo com Cosson (2010, p. 56), a literatura ocupava o mesmo espaço que o ensino da leitura e da escrita, pois esteve presente na sala de aula como a matéria que contribuía com a conexão entre a escola, a língua e a sociedade, sendo a própria essência de uma formação humanista. Entretanto, a literatura foi adquirindo um outro lugar, tornou-se, sobretudo, uma ferramenta utilizada apenas para o ensino de gramática e de outras abordagens consideradas mais enriquecedoras para a proposta curricular de ensino.

Para Silva (2003, p. 514), as relações entre leitura, literatura e escola são, muitas vezes, desfeitas nas práticas de sala de aula. Segundo a autora, o ensino de língua tem priorizado com atividade frequente, no espaço escolar, apenas a utilização dos livros didáticos como instrumento principal para a experiência com a literatura.

Isso acontece porque o objetivo da leitura literária em sala de aula restringe-se, em muitos casos, à realização de tarefas escolares. Raramente são explicadas e mostradas aos alunos as variadas formas de interpretar, de compreender o sentido do texto, relacionando-o ao contexto e às vivências sociais. Dessa forma, as aulas de literatura se tornam entediantes, formando alunos incapazes de apreciar a literatura.

Os documentos oficiais, Base Nacional Comum Curricular - BNCC (2017), os Parâmetros Curriculares Nacionais - PCN (1998) e o Documento Curricular Referencial do Ceará- DCRC (2019), ${ }^{4}$ no ensino de Língua Portuguesa, apontam que a atividade com o texto literário deve ser frequente e contínua e que ele "esteja incorporado às práticas cotidianas da sala de aula, visto tratar-se de uma forma específica de conhecimento.” (BRASIL, 1998, p. 29).

Lajolo (2000, p. 11) reforça que "o que fazer com ou do texto literário em sala de aula funda-se, ou devia fundar-se, em uma concepção de literatura muitas vezes deixada de lado em discussões pedagógicas". É necessário que a escola amplie o conjunto de atividades, objetivando a leitura literária como prática lúdica de construção e reconstrução de sentidos, proporcionando o encontro do aluno com o texto, permitindo que o leitor se reconheça, se identifique na obra, que perceba que sua cultura pode talvez estar atrelada ao texto lido.

\footnotetext{
${ }^{4} \mathrm{O}$ Documento Curricular Referencial do Ceará (DCRC) foi elaborado pelo estado do Ceará, à luz da BNCC, em regime de colaboração com seus municípios.
} 
Nessa perspectiva, Rouxel (2013) nos faz refletir e questionar quais são as finalidades e os objetivos do ensino da literatura. Uma delas diz respeito ao que deve ser feito sobre o propósito do ensino da literatura, tais como "para quê? O para quê determina o como. Finalidades e métodos estão ligados. Trata-se de aumentar a cultura dos alunos? (qual cultura?), de formar leitores? De contribuir para a construção de suas identidades" (ROUXEL, 2013, p. 17).

Notamos que a autora corrobora as ideias de Lajolo (2000) quando defende um ensino de literatura que vise à formação crítica e à construção e reconstrução de sentidos que podem ser atingidos através da maneira como o professor conduz o texto literário.

Com isso, Dalvi (2013, p. 75) ressalta que, na escola, "os textos literários são apresentados em desarticulação com o mundo da vida, com a história e o contexto social-econômico-cultural."

Soares (2006) faz uma relevante reflexão quando reforça que é inevitável a escolarização da literatura, já é da essência da escola isso acontecer, entretanto, a autora salienta que seja valorizado o potencial literário.

Ainda para essa autora, uma escolarização adequada da literatura conduz ao letramento literário, uma vez que deve encaminhar a uma prática de leitura literária eficaz, que ultrapasse os muros da escola. Assim, o leitor seria capaz de interpretar, construindo conexões entre o texto e o contexto.

O ambiente escolar, por sua vez, é o espaço onde o aluno, de fato, se depara com o ato de ler mais sistematizado. Com isso, o processo de escolarização da leitura e da literatura deve ser levado em consideração, visto que é objetivo da escola contribuir para o processo de letramento literário.

Para Cosson (2018a, p. 120), o letramento literário vai além da leitura literária. O autor diz que ser um leitor letrado "é mais do que fruir um livro de fícção ou se deliciar com as palavras exatas da poesia. É também posicionar-se diante da obra literária”. Isso significa dizer que a leitura do texto literário, além de proporcionar prazer, "fornece os instrumentos necessários para conhecer e articular com proficiência o mundo feito linguagem” (COSSON, 2018a, p. 30).

Com isso, o autor destaca por que o letramento literário é tão relevante ao processo educativo ao frisar que a leitura literária, na escola, tem como propósito melhorar a qualidade da leitura e enriquecê-la, porque fornece ao leitor ferramentas de conhecimento para tornar-se proficiente no mundo da linguagem através da reflexão, ou seja, na formação de sujeitos cidadãos.

O autor ainda afirma que "para que a literatura cumpra seu papel humanizador, precisamos mudar os rumos da sua escolarização, [...] promovendo o letramento literário.” (COSSON, 2018a, p. 17).

Entende-se, portanto, que a literatura só poderá tornar-se uma ferramenta poderosa de humanização e transformação dentro da escola caso haja mudanças no sistema educacional da maioria das escolas brasileiras, pois o letramento do educando precisa ser um dos objetivos principais do ensino no Brasil.

\section{LETRAMENTO LITERÁRIO E OS MULTILETRAMENTOS INSERIDOS EM UM CONTEXTO PLURAL DE LINGUAGENS}

Compreender o letramento literário entrelaçando-o às concepções da pedagogia dos multiletramentos é pensar em um ensino que proporcione as multiplicidades de linguagens e de acesso aos bens culturais, à comunicação e à informação. Isso porque no cotidiano das escolas, na contemporaneidade, as práticas sociais estão inseridas em um contexto dinâmico e plural.

Nessa perspectiva, a literatura, também, está incorporada nesse ambiente da pluralidade de linguagens. Com isso, nas diversas práticas sociais contemporâneas, o processo comunicativo 
acontece não apenas pela linguagem verbal, mas também por meio de imagens, sons, gestos entre outros recursos semióticos.

Dessa forma, o trabalho articulado para a dimensão da pedagogia dos multiletramentos pode ser direcionado ao desenvolvimento de atividades de ensino e aprendizagem voltadas para o exercício da leitura e da escrita que considerem as diversas práticas sociais da linguagem e dos textos multimodais aliando, por exemplo, de forma interativa, o visual e o verbal no processo de leitura, sobretudo, a literária.

Rojo e Moura (2012) discutem o conceito de multiletramentos, contextualizando-os numa dinâmica social e cultural que medeia semioses. Para esses autores:

Diferentemente do conceito de letramento (múltiplos), que não faz senão apontar para a multiplicidade e variedade das práticas letradas, valorizadas ou não nas sociedades em geral, o conceito de multiletramentos - é bom enfatizar - aponta para dois tipos específicos e importantes de multiplicidade presentes em nossas sociedades, principalmente urbanas, na contemporaneidade: a multiplicidade cultural das populações e a multiplicidade semiótica de constituição dos textos por meio dos quais ela se informa e se comunica (ROJO, MOURA, 2012, p. 13).

Os multiletramentos, assim, proporcionam a construção de sentidos a partir de múltiplos textos que, de forma multimodal, permitem a aprendizagem em prática cotidiana.

As semioses representadas por imagem, cor, som, textura, tipografia, palavras, movimento apresentam valor informativo na produção de sentidos do texto, constituindo-se, assim, a multimodalidade, que se refere, de acordo com Vieira e Silvestre (2015), às múltiplas semioses presentes nos textos que circulam na sociedade.

Nesse sentido, entendemos que o trabalho com a leitura de textos, em uma sociedade multimídia, deve, também, utilizar-se dos elementos visuais (imagens, sons, movimentos, cores, diagramação, formatos e destaques) para a construção de sentidos, uma vez que esses elementos são significativos e contribuem para o processo de comunicação.

Nessa perspectiva, consideramos que a análise multimodal/multissemiótica é essencial no ensino de língua portuguesa, pois ajuda a interpretar os contextos sociais e culturais, contribuindo para que o sujeito possa discernir a respeito do mundo multimodal.

De acordo com a Base Nacional Comum Curricular - BNCC, "as práticas de multiletramentos" são constituídas por meio das práticas de leitura e produção de textos construídos a partir de diferentes linguagens ou semioses "na medida em que exigem letramentos em diversas linguagens, como as visuais, as sonoras, as verbais e as corporais" (BNCC 2017, p. 487).

Assim, a BNCC reforça a necessidade da inserção da pedagogia dos multiletramentos na prática educacional e ressalta como o trabalho com a multimodalidade pode contribuir no processo de aprendizagem dos educandos, favorecendo um ensino crítico, além de tornar as aulas de língua portuguesa mais significativas para o aluno.

O texto multimodal, dessa forma, configura-se como "uma unidade de significação, constituída pelos recursos semióticos dos diversos sistemas escolhidos pelo produtor de texto, num contexto de situação, para determinados fins comunicativos" (VIEIRA; SILVESTRE, 2015, p. 98).

Diante disso, buscamos refletir sobre a importância da articulação dos recursos visuais e imagéticos para a constituição dos sentidos de textos literários considerando a dimensão interacionista da linguagem. Compreendemos, dessa forma, como os recursos da linguagem verbal e das imagens podem ser empregados de forma interativa para construir diferentes tipos de significados e para efetivar práticas de linguagem. Isso representa uma habilidade inerente aos pressupostos dos multiletramentos para construção de sentido do texto literário e formação do leitor letrado e protagonista. 
Em uma prática pedagógica que utilize a pedagogia dos multiletramentos, os recursos multimodais são significativos, pois representam pistas que favorecerão a uma leitura mais proficiente, conforme apontam Vieira e Silvestre:

[...] todos os elementos provenientes de sistemas semióticos diversos que co-ocorrem nos textos multimodais podem ser analisados, relacionados uns com os outros e interpretados em termos das escolhas feitas entre os recursos semióticos disponíveis e em termos das suas contribuições para a função social e comunicativa do texto. O significado do texto não é, por conseguinte, produzido unicamente por um único modo, mas pela composição dos diversos elementos (VIEIRA; SILVESTRE, 2015, p. 100-101).

Os textos multimodais apresentam, dessa forma, potencialidades para uma ressignificação do processo de leitura, uma vez que os diferentes recursos semióticos possibilitam a construção dos sentidos do texto. Nessa dimensão da multimodalidade, consideramos que palavra e imagem juntas não correspondem às formas semelhantes de se dizer a mesma coisa; palavra significa mais quando acompanhada da imagem. Por sua vez, a imagem nem sempre transmitirá a mesma mensagem que o texto escrito, a imagem também significa mais quando acompanhada do escrito (KRESS, VAN LEEUWEN 1996, 2006).

Em um texto multimodal, o sujeito pode, de forma autônoma, escolher entre um ou outro modo de linguagem para determinada representação, de acordo com o efeito semiótico que pretende utilizar. Cada uma dessas linguagens pode atingir determinado propósito comunicativo e, quando articuladas, o potencial funcional é mais diversificado.

A pedagogia dos multiletramentos possibilita ao professor, em sua prática docente, utilizar os diferentes recursos semióticos inseridos no contexto de vivência do educando. Esses recursos constituem-se como instrumentos de interação e comunicação, assim o sujeito torna-se o sujeito de sua aprendizagem, produtor de saber e leitor autônomo (ROJO, 2009).

Consideramos que são diversas as possibilidades de leitura de textos com o uso das diferentes semioses na construção de sentido. Salientamos que, neste trabalho de pesquisa, voltado para a leitura literária, na perspectiva de promover o letramento literário, optamos por uma abordagem que buscasse a articulação entre o recurso verbal e visual no processo de leitura que exige interpretações e apreensões das linguagens contextuais num diálogo crítico, imaginativo e reflexivo.

\section{METODOLOGIA: O VERBAL E O VISUAL NA CONSOLIDAÇÃO DE SUJEITOS LETRADOS}

Esta pesquisa, de abordagem qualitativa, se caracteriza como pesquisa-ação, que, para Thiollent, permite aos pesquisadores se envolverem "de modo cooperativo e participativo" (THIOLLENT, 1996, p. 13).

O trabalho envolveu alunos de uma turma de $7^{\circ}$ ano do Ensino Fundamental, anos finais, em uma escola de Rede Pública de Fortaleza em sala de aula de Língua Portuguesa. Para tanto, foram realizadas atividades que unissem aspectos visuais e verbais no processo de leitura literária. A obra proposta para esse trabalho foi O Gralha, menino de rua, de Lourdes Carolina Gagete.

Como sugestões de atividades, utilizamos a Sequência Básica (SB) e o Círculo de Leituras (CL) proposto por Cosson (2018a, 2018b) e o Diário de Leituras (DL) proposto por Cosson (2018b), Buzzo (2003, 2010) e Machado (2005). 
Para as análises, utilizamos como instrumentos, as produções no DL, e a produção dos cartazes para o CL. Nessa perspectiva, essa análise aconteceu à luz dos autores que versam sobre o trabalho com o texto literário, dialogando com teóricos que abordam as concepções do multiletramentos como Kress e Van Leeuwen (1999, 2006), Rojo e Moura (2012) dentre outros. No processo de leitura literária, componentes da multimodalidade, especificamente, o aspecto visual, foram constitutivos para compreensão e diálogo do aluno com a obra literária.

Ressaltamos que, para a análise da pesquisa, tivemos como documentos 25 (vinte e cinco) diários e 9 (nove) cartazes produzidos pelos educandos. Entretanto, neste artigo, apresentamos apenas um recorte de alguns trechos desses escritos, identificados pelas siglas dos nomes dos educandos.

Assim, para a organização e aplicação das atividades de leitura literária na escola, utilizamos a Sequência Básica (SB) proposta por Cosson (2018a) que será apresentada a seguir:

\section{SEQUÊNCIA BÁSICA (SB)}

Cosson (2018a) organiza a SB em quatro etapas: Motivação, Introdução, Leitura e Interpretação. A primeira etapa da SB, a Motivação, constitui-se como essencial para motivar o aluno no processo de leitura literária. Esta etapa, segundo esse autor, "prepara o leitor para receber o texto", mas ainda não é a leitura propriamente da obra a qual se propõe para o processo de leitura. Com isso, este momento pode ser introduzido por meio da leitura de outros textos, também com realização de dinâmicas, apresentação de vídeos, e outros materiais que possam "exercer uma influência sobre as expectativas do leitor" (COSSON, 2018a, p. 56).

Dessa forma, optamos por iniciar essa primeira etapa com a leitura do texto imagem CENAS $D E R U A$, de Ângela Lago porque ele apresenta uma conexão muito relevante com a temática da obra $O$ Gralha, menino de rua, oportunizando um momento de reflexão. Assim, fomos fazendo vários questionamentos aos educandos sobre as cenas do livro. Dentre esses questionamentos temos: como as pessoas reagem quando o garoto se aproxima para vender os bombons?

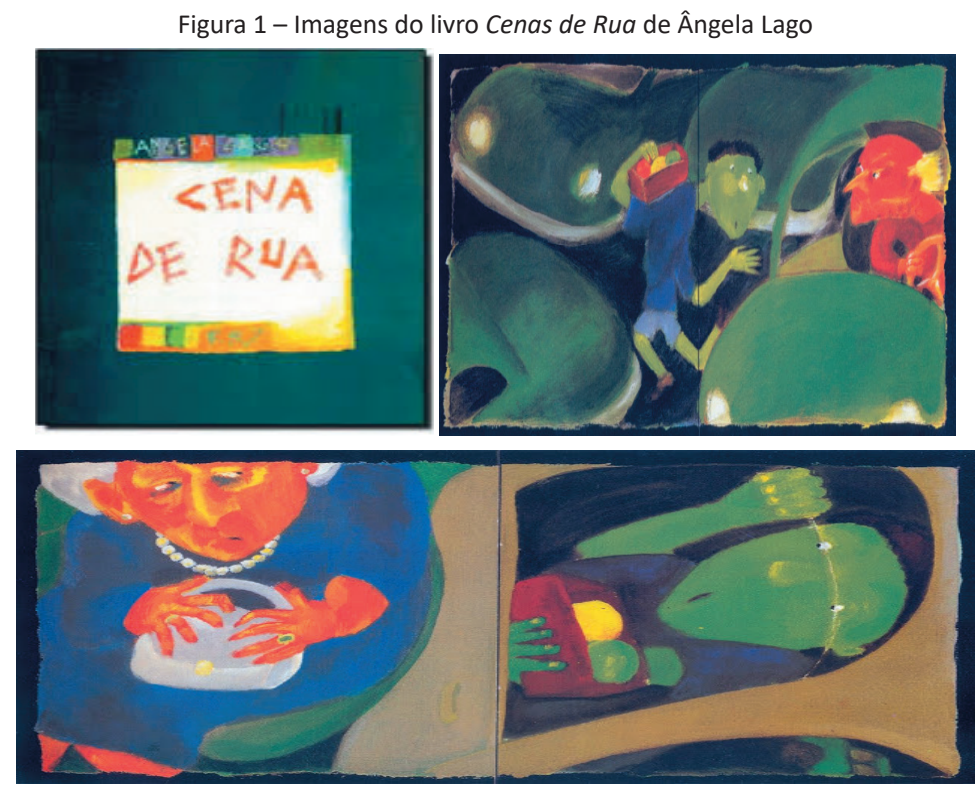



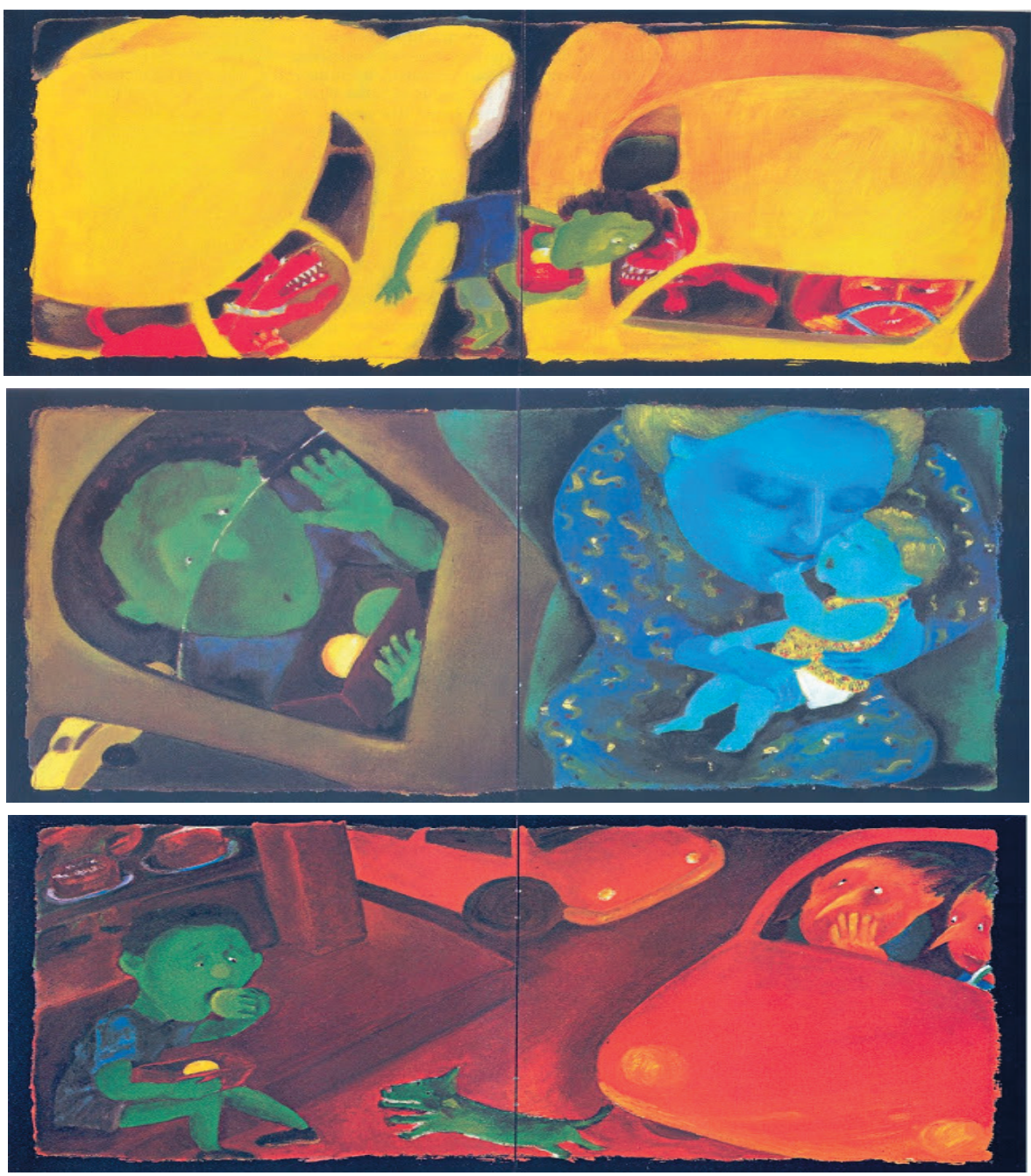

Ilustrações: Lago (1994)

Sentimos uma grande sensibilização da turma quando afirmou que, na maioria das vezes, a sociedade cria, diante dessa realidade social, um olhar de desprezo. Quando apresentamos a imagem da mulher segurando a bolsa com medo de ser assaltada, todos os alunos afirmaram que essa é a reação mais comum das pessoas. A imagem da mãe dentro do carro dando carinho ao seu filho foi uma cena que trouxe ao mesmo tempo aos alunos um ar de alegria, mas também de tristeza por saberem que há muitos jovens que não têm mais a presença dos pais, da família, do lar.

Reforçamos o que pensa Rojo (2012), ao tratar da multimodalidade e da multissemiose, esclarecendo que as atividades de leitura semiótica dos textos nos possibilitam conhecer diferentes formas de representação da leitura de imagem.

Dando continuidade à SB, iniciamos a segunda etapa, a Introdução. Ela visa apresentar o autor e a obra. Decidimos iniciar esse momento logo após a etapa da motivação, no mesmo encontro, por favorecer uma maior associação da sequência reflexiva de ideias programadas na primeira etapa com a temática a ser abordada no livro.

Apresentamos, então, aos alunos o primeiro contato com a obra: O Gralha, menino de rua. 


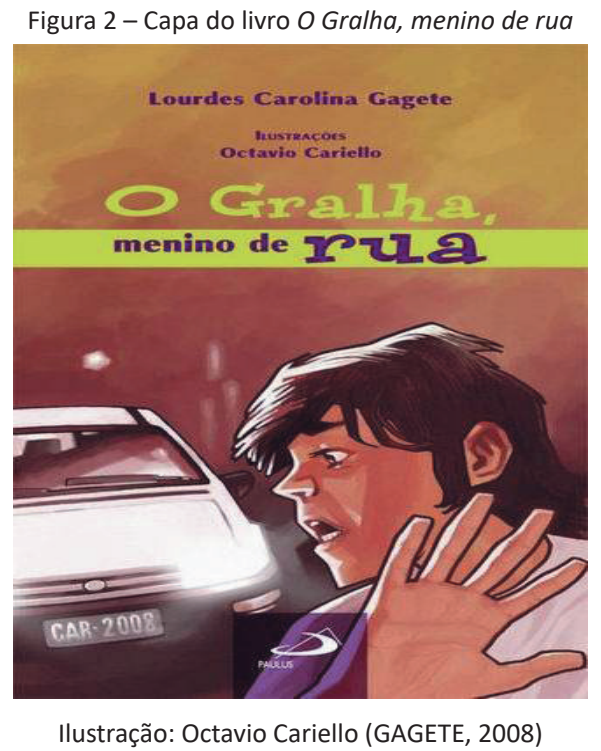

Cada um dos alunos recebeu um exemplar e, espontaneamente, folhearam o livro. Solicitamos que atentassem para a capa, o prefácio, as orelhas, o título, a ilustração e outros elementos paratextuais da obra. O objetivo era instigar a curiosidade e o interesse pela leitura.

Com a mediação do pesquisador foram feitas as seguintes inferências: na imagem da capa, quem vocês acham que seja esse garoto? Qual o título do livro? Vocês acham que existe relação do título com a imagem do garoto? O que significa Gralha? É um nome próprio?

Muitos educandos afirmaram não saber o significado da palavra "gralha", mas relataram que possivelmente seria o nome do "menino de rua" porque, para eles, o título trazia essa pista. Outros alunos aguçaram seu conhecimento de mundo quando afirmaram que "gralha" se referia a um pássaro, o que gerou reflexões para entender o porquê de o personagem receber essa denominação, o que só foi descoberto durante a leitura propriamente da obra.

Esse momento, bastante interativo e produtivo, favoreceu o levantamento do conhecimento prévio, as opiniões e o interesse pela leitura do livro. Isso favoreceu um trabalho colaborativo na construção de sentido do texto.

Seguimos para o terceiro passo da SB, a Leitura. Ela está na leitura propriamente dita da obra. Nesta etapa, o mais importante é o acompanhamento da leitura que não pode deixar de ser bem direcionada por se tratar de uma ação fundamental para a proposta do letramento literário (COSSON, 2018a).

Nossos momentos para a leitura do livro aconteceram em 7 (sete) encontros com duração de 14 (quatorze) horas aula. A cada início de leitura era retomada a leitura anterior para que pudéssemos fazer um feedback da compreensão do texto e, ao final de cada dia de leitura, o aluno era motivado por meio de questionamento para o assunto, acontecimento e ação dos personagens que estavam por acontecer, por exemplo, nas páginas seguintes, como forma de aguçar o seu interesse nas próximas leituras.

O processo dessa etapa foi favorecido pelas leituras e inferências das diversas ilustrações presentes na obra.

Segundo Acaso (2006), o ato de ver não é uma ação estanque e isolada, ou seja, não é um olhar superficial, mas envolve transformação do nosso conhecimento, assim o visual aciona a nossa 
sensibilidade, enriquecendo o que é lido e interpretado. A linguagem imagética auxilia o leitor a compor a narrativa.

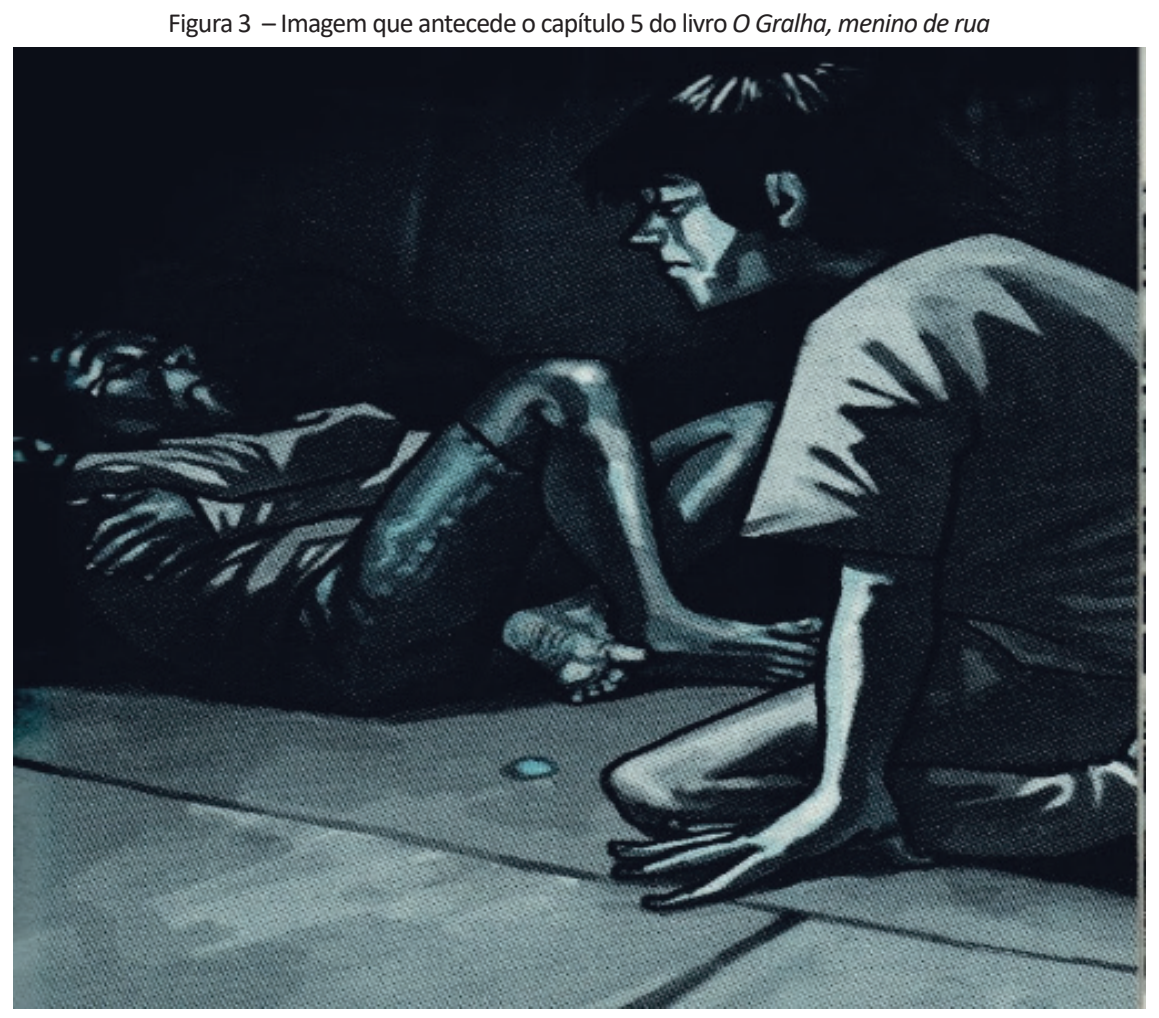

Fonte: Ilustração de Octavio Cariello (GAGETE, 2008, p. 37)

Notamos que houve, diante da Figura 3, um olhar de sensibilidade do leitor que foi, com a mediação do professor, fazendo inferências e reflexões quanto à cena ilustrada: Quem seriam esses personagens? Que sensações eram transmitidas pela fisionomia de cada um? Essas reflexões foram importantes também para motivar, conduzir e introduzir a leitura do capítulo subsequente.

Os educandos expuseram que, nessa cena, se visualizava um sentimento de "tristeza e "dor". Para os leitores, o personagem deitado ao chão estaria sofrendo, possivelmente, as consequências decorrentes da fome e do uso de drogas. Destacaram também o sentimento de "solidariedade" ao se observar a presença do protagonista diante daquele personagem na tentativa de ajudá-lo.

Compreendemos que ilustração não funciona de forma meramente decorativa. Ela une uma variedade de signos ideológicos capazes de promover, num processo dialógico, esse olhar sensível do leitor observador. Assim, tais fundamentos relacionam-se aos preceitos bakhtinianos sobre as interações dialógicas e ideológicas constituintes de uma linguagem valorizada culturalmente que vem vinculada aos estudos da imagem em situações de produção e compreensão literária.

Chegamos ao último passo da SB, a Interpretação. Etapa em que se chega à construção do sentido do texto. O marco desse momento é o registro (COSSON, 2018a).

Esses registros foram concretizados com a produção de cartazes, ao final da leitura literária, apresentados e expostos num mural, constituindo o círculo de leituras bem como, registro das produções dos educandos, ao longo da leitura, no diário de leituras. Esses materiais constituem instrumentos de análise e serão explicitados a seguir. 


\section{CÍRCULO DE LEITURAS (CL)}

Os círculos de leitura são práticas em que ocorrem compartilhamento de leituras de uma determinada obra, possibilitando um momento efetivo de interação entre os leitores e os textos literários, uma vez que, durante a troca de informações entre os participantes, as percepções de cada leitor são aguçadas, ampliando-se, com isso, a sua própria experiência.

Assim, o CL forma uma comunidade de leitores, dentro ou fora da escola, já que a "leitura é, assim, um processo de compartilhamento, uma competência social" (COSSON, 2018, p. 36), o que permite uma socialização entre os envolvidos.

Para essa atividade, organizamos os alunos em grupos de, aproximadamente, 4 (quatro) participantes para a produção de cartazes. Cada grupo escolhia uma das funções, assim denominadas: conector, questionador, iluminador de passagens, dicionarista, sintetizador, perfilador, cenógrafo, ilustrador e pesquisador. Esse modelo de atividade, denominado fichas de função, foi elaborado por Harvey Daniels (2002) e, segundo Cosson (2018a, p. 140), é de grande contribuição para o processo de leitura do texto literário.

Essas funções, segundo Harvey Daniel (2002) são, resumidamente, assim descritas:

a) Conector: faz conexões do texto lido com as vivências dos educandos;

b) Questionador: elabora questões sobre a obra;

c) Iluminador de passagem: seleciona passagem do texto para explicitar;

d) Ilustrador: busca imagens para ilustrar o texto;

e) Dicionarista: seleciona palavras difíceis ou relevantes para leitura;

f) Sintetizador: resume a obra;

g) Pesquisador: busca informações contextuais que considere relevantes;

h) Cenógrafo: descreve as cenas mais importantes;

i) Perfilador: Traça um perfil dos personagens.

Percebemos que o círculo de leituras é "uma prática privilegiada" uma vez que permite aos educandos, uma leitura literária colaborativa e interativa, ou seja, "ao lerem juntos, os participantes do grupo tornam explícito o caráter social da interpretação dos textos" (COSSON, 2018b, p. 139), proporcionando um diálogo do leitor com a obra. Esses registros apresentam reflexões e sensações dos leitores sobre a obra lida. Salientamos que esses materiais foram fundamentais para o processo de constituição do letramento literário.

Figura 4 - Círculo de leituras: produção, apresentação e exposição dos cartazes no mural com as funções de cada grupo.

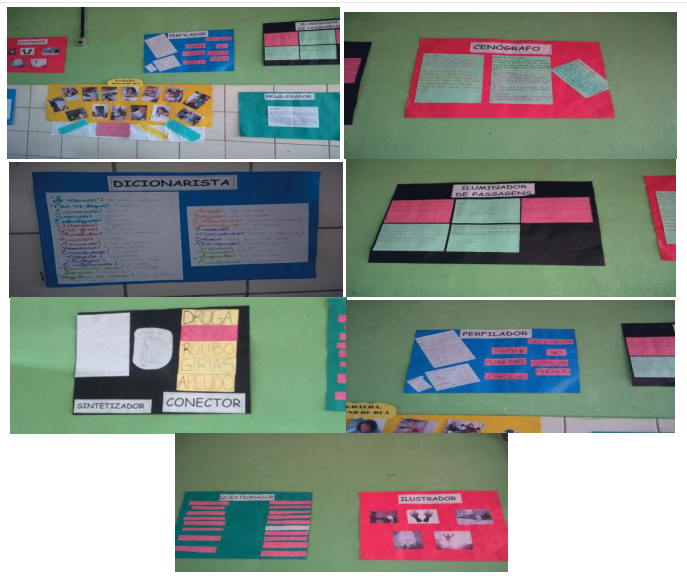

Fonte: Produzidos pelos alunos. 
Assim, especificamente, na função de ilustrador, os alunos apontaram, por meio de ilustrações, as principais cenas da obra, como mostra o cartaz da Figura 5. A forma de apresentação do trabalho pelos educandos ficou bem interessante porque eles distribuíram as imagens para que os demais colegas da sala, durante o CL, descobrissem a qual capítulo do livro essas imagens estavam associadas. Os capítulos da obra sequencialmente destacados foram $O$ roubo, Os pés de Aurélia, A morte do Saci, O casamento de Mariana e Epílogo.

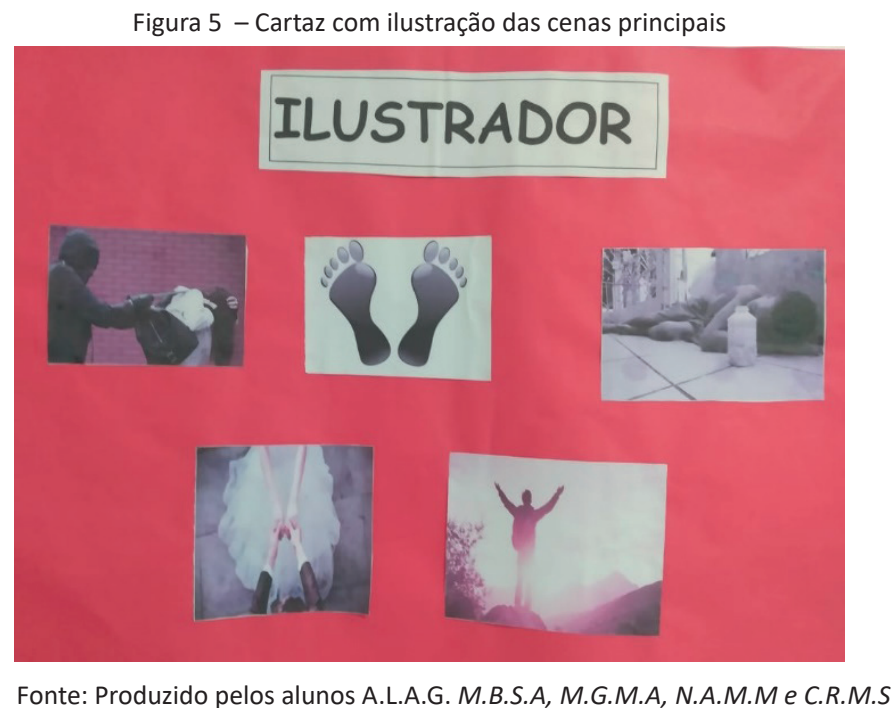

Essa ressignificação por meio dos recursos semióticos, aliando visual e verbal, utilizados pelos educandos, potencializou a compreensão do sentido do texto por parte do leitor (KRESS, VAN LEEUWEN, 1996, 2006).

\section{DIÁRIO DE LEITURAS (DL)}

O diário de leituras é um gênero discursivo que traz, como informações principais, as ideias do leitor sobre suas concepções leitoras. Segundo Machado (2005), o diário de leituras é um texto produzido por um leitor, à medida em que lê, com o objetivo maior de dialogar, de conversar com o autor do texto, de forma reflexiva (MACHADO, 2005, p. 64).

O educando, ao fazer o registro de sua leitura literária, poderá avaliar a narrativa, resumir, comentar, expressar suas dúvidas, estabelecer relações entre o texto literário e suas vivências, revelar possíveis contribuições proporcionadas pelo texto literário. Nessa perspectiva, Rildo Cosson compreende o diário de leituras como

[...] registro das impressões do leitor durante a leitura do livro, podendo versar sobre dificuldades de compreensão de determinadas palavras e trechos, transcrição de trechos favoritos com observações, evocação de alguma vivência, relação com outros textos lidos, apreciação de recursos textuais, avaliação da ação das personagens, identificação de referências históricas e outros tantos recursos que constituem a leitura como um diálogo registrado entre leitor e texto (COSSON, 2018b, p. 122). 
A prática do DL por meio da experiência com a leitura literária possibilita aos alunos aprimorar a aquisição de conhecimentos, pois desenvolve no leitor o seu posicionamento crítico diante dos textos. Assim, para Buzzo (2010), o diário de leituras possibilita "ao leitor ultrapassar os limites da compreensão, ao tecer comentários, a relacionar o texto lido com conhecimentos prévios" (BUZZO, 2010, p. 17).

O diário permite estabelecer uma relação dialógica entre o leitor e o autor do texto (BUZZO, 2010). Essa interação pode ocorrer de forma reflexiva, possibilitando, além da compreensão do texto, liberdade de expressão, de forma que o educando reflita criticamente sobre o que é lido e produzido nos registros dos diários, auxiliando, assim, no processo de letramento literário, funcionando como um elemento motivador e incentivador às novas leituras.

Nessa perspectiva, o DL foi adotado em nossa pesquisa como instrumento para que os estudantes, de forma espontânea, registrassem as suas impressões suscitadas pela leitura da obra $O$ Gralha, menino de rua. A produção no DL, mediada pelo professor, aconteceu durante e após os momentos de leitura literária na escola.

Como já foi ressaltado anteriormente, apresentaremos apenas a análise de um recorte de alguns trechos dos diários produzidos pelos educandos, identificados pelas siglas dos seus nomes.

Reforçamos que a análise dos resultados desses registros aconteceu em um diálogo com diversos autores como Cosson (2018a, 2018b), Buzzo (2003, 2010), ${ }^{5}$ Coscarelli (2009), Kress e Van Leeuwen (1996, 2006), Vieira e Silvestre (2015) dentre outros, como será explicitado nas Figuras 6,7 e 8 .

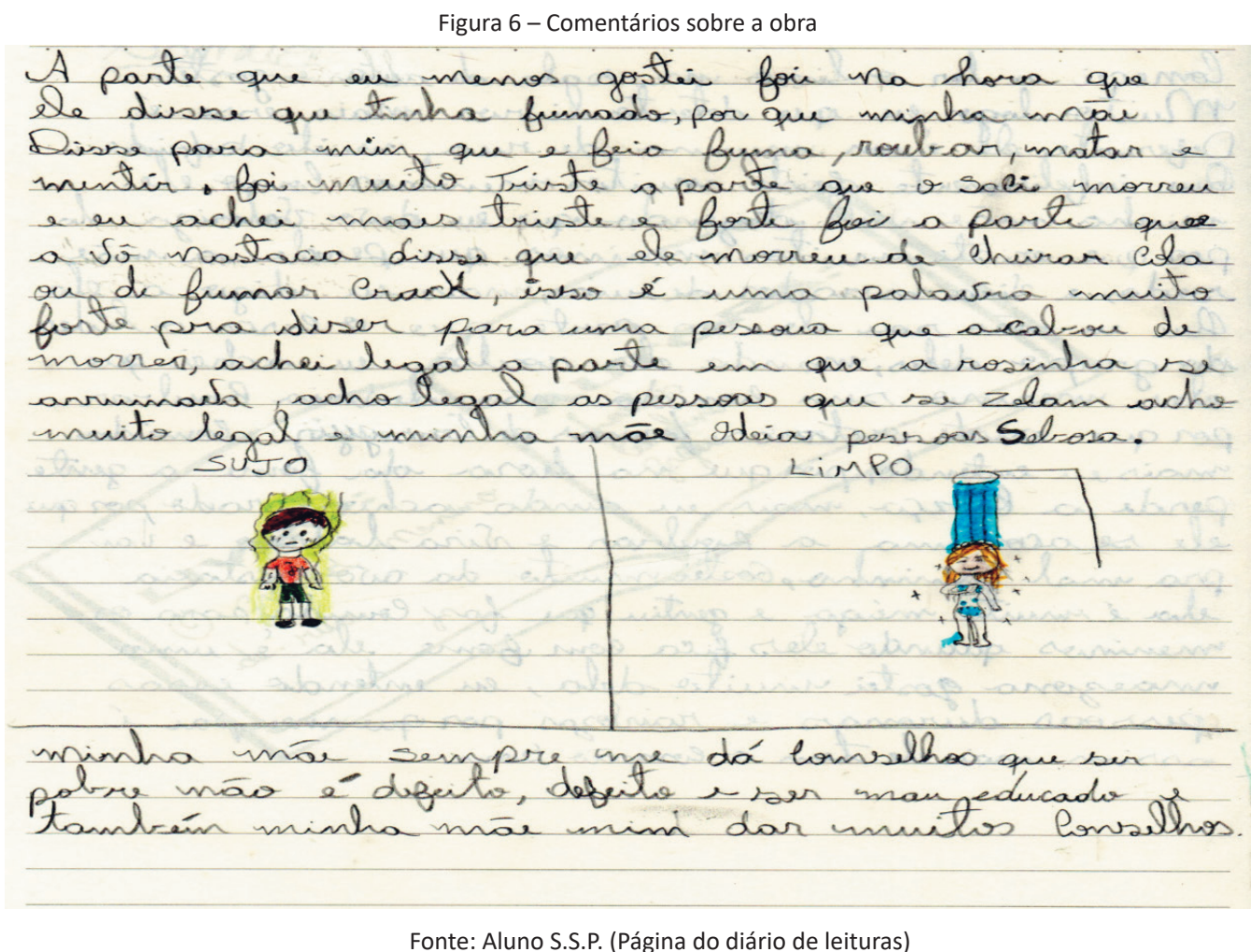

\footnotetext{
${ }^{5}$ Buzzo $(2003,2010)$ apresenta as seguintes categorias de interpretação do gênero diarista: avaliações, resumos, comentários dúvidas, relações e contribuições,
} 
O comentário sobre a obra, representado pela Figura 6, é exemplificado por meio da escrita e dos desenhos do educando a uma experiência da narrativa em que o protagonista da obra é posto a tomar banho quando estava hospitalizado. Isso despertou no leitor uma relação de situações de seu cotidiano e aos conselhos relatados pela sua mãe. Tal situação dialoga, nesse contexto, com o pensamento de Kress e Van Leeuwen $(1996,2006)$ quando ressalta que a linguagem visual não serve apenas como mero complemento da linguagem verbal, as imagens se configuram como um importante veículo de comunicação.

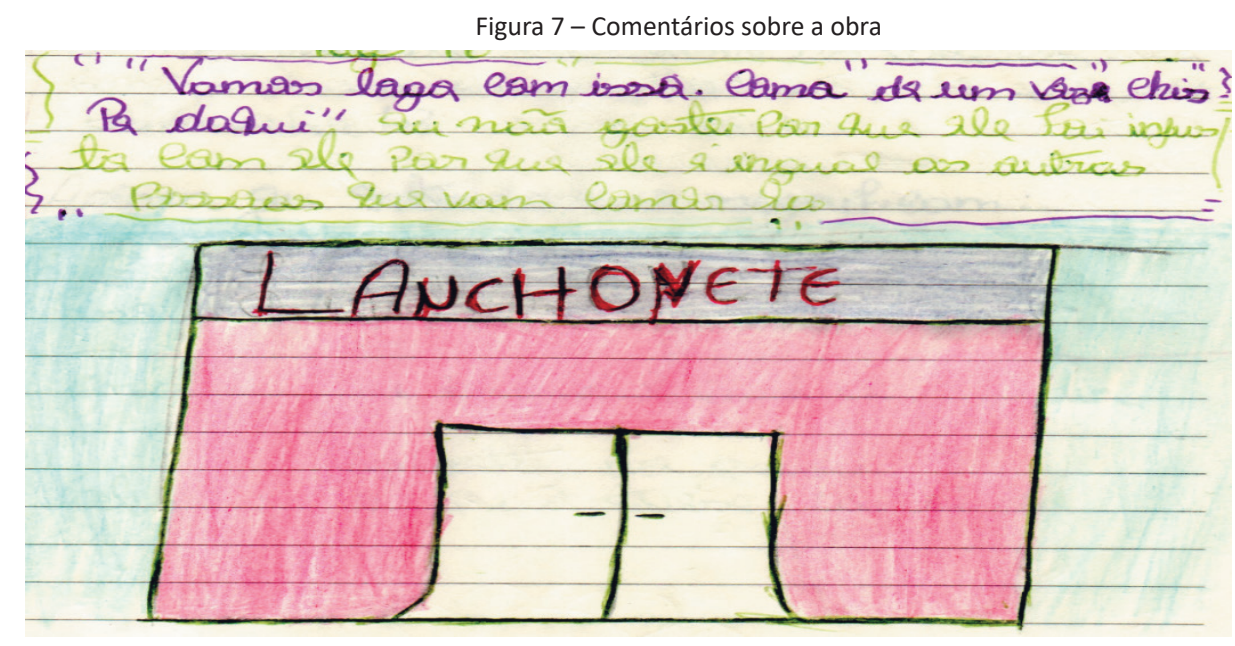

Fonte: Aluno V.A.S (Página do diário de leituras)

Essa cena, na narrativa, aconteceu numa lanchonete quando uma senhora com olhos de amor convidou o Gralha a escolher o que quisesse comer, mas o dono da padaria sentiu-se incomodado "vamos logo com isso. Coma de uma vez e chispe daqui". O leitor achou tal atitude uma situação de injustiça, uma vez que todos somos iguais.

Na Figura 7, confirmamos o pensamento de Vieira e Silvestre (2015), quando salientam que as semioses desempenham papel importante na reconfiguração da linguagem, "tendo em vista que as representações realizadas por meio de imagens e das cores, por exemplo, aproximam mais o discurso representado da realidade" (VIEIRA, SILVESTRE, 2015, p. 17).

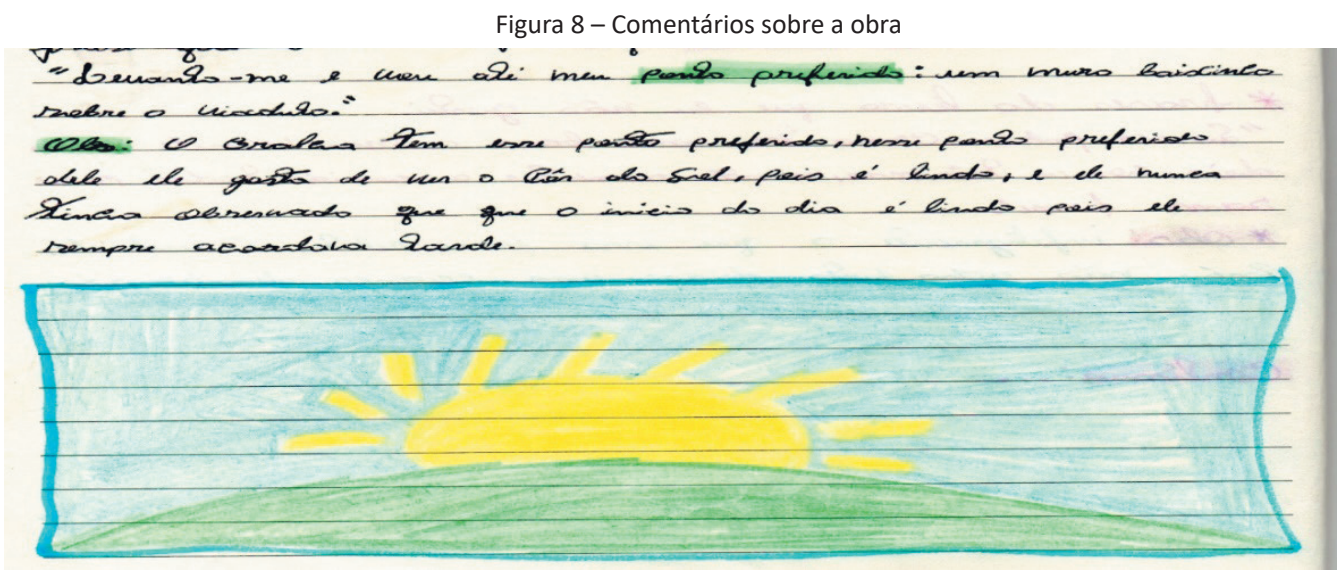

Fonte: Aluno A.N.M. (Página do diário de leituras) 
A aluna, na figura 8, faz um comentário de um fragmento que ela considerou interessante no livro e que é narrado pelo protagonista Gralha "Levanto-me e vou até meu ponto preferido: um muro baixinho sobre o viaduto". (GAGETE, 2008, p. 33). A leitora explica o trecho dizendo: $o$ gralha tem esse ponto preferido, nesse ponto preferido dele ele gosta de um pôr do sol, pois é lindo, e ele nunca tinha observado que o início do dia é lindo pois ele sempre acordava tarde. Ela percebe a beleza desse lugar, que é ilustrado pelo desenho do pôr do sol.

A imagem, conforme Kress e Van Leeuwen (1996, 2006), representa a relação entre as pessoas, os lugares e as coisas que se aliam ao conjunto de conexões que podem, e entre as imagens e os leitores. Ela, segundo Coscarelli (2009), é constitutiva na compreensão do texto, ou seja, a imagem não apenas ilustra, ela complementa o texto verbal.

Compreendemos que, em uma análise multimodal, o recurso visual, representado pelos desenhos dos educandos, nas figuras 6, 7 e 8, aconteceu de forma articulada com o que os alunos interpretaram durante o processo de leitura literária. Assim, para Kress (2003), um texto multimodal é compreendido como o resultado de uma ação social.

\section{CONSIDERAÇÕES FINAIS}

O trabalho com o texto literário à luz da proposta dos multiletramentos, nesta pesquisa, possibilitou-nos compreender o quanto é pertinente inserir, no contexto de ensino, a convivência com os textos semióticos que contribuem para a formação do leitor contemporâneo e, assim, buscar inserir o educando num contexto de letramento diverso, especificamente, o letramento literário.

As propostas metodológicas permitiram que os discentes dialogassem com o texto literário, que expressassem sua compreensão e suas sensações por meio da escrita, das imagens, das cores, de forma criativa e interativa, aliando o visual e o verbal, privilegiando um olhar crítico e reflexivo.

Compreendemos que a prática de letramento literário, que se consolidou mediante a leitura literária, deva dialogar com as diversas possibilidades de letramentos, permitindo, nesse processo de leitura, aos educandos, múltiplos olhares para compreensão da sua realidade e, com isso, a valorização da sua experiência social e cultural.

\section{REFERÊNCIAS}

ACASO, María. La diferencia entre ver y leer. In: . Esto no son las torres gemelas: como aprender a leer la televísion y otras imágenes. Madrid: Catarata, 2006, p. 89-91.

BAKTHIN, Mikhail M.; VOLOCHÍNOV, V.N. A interação verbal. In . Marxismo e filosofia da linguagem. 12.ed. Tradução Michel Lahud e Yara Frateschi Vieira. São Paulo: HUCITEC, 2010. cap.6, p.112-130

BRASIL. Base Nacional Comum Curricular (BNCC). Educação é a Base. Brasília, MEC/CONSED/ UNDIME, 2017. Disponível em: http://basenacionalcomum.mec.gov.br/images/BNCC_EI_ EF_110518_versaofinal_site.pdf Acesso em: 01 de outubro de 2019. 
BRASIL, Parâmetros Curriculares Nacionais: Língua Portuguesa. Brasília: MEC, 1998.

BUZZO, M. G. O diário de leitura como artefato ou instrumento no trabalho docente. Revista L@ el em (Dis-)curso. Volume 2, 2010. Disponível em: http://revistas.pucsp.br/revlael/article/ view/1041/2565. Acesso em 17.09.2019

BUZZO, M. G. O Diário de Leituras: uma experiência didática na Educação de Jovens e Adultos (EJA). Dissertação de Mestrado em Linguística Aplicada e Estudos da Linguagem. São Paulo: PUC-SP, 2003. (Mestrado em Linguística e Estudos da Linguagem) - PUC-SP- Orientadora: Dra. Anna Rachel Machado.

CEARÁ. Documento Curricular Referencial do Ceará (DCRC). Governo do Estado do Ceará. 2019. Disponível em http://basenacionalcomum.mec.gov.br/images/implementacao/curriculos_estados/documento_curricular_ce.pdf. Acesso em 17 de outubro de 2019.

COSCARELLI, C.V. Textos e hipertextos: procurando o equilíbrio. Linguagem em (Dis)curso, Palhoça, SC, v.9, n. 3, p. 549 - 564, set./dez. 2009.

COSSON, Rildo. Letramento literário: teoria e prática. 2. ed., 7 impressão. São Paulo: Contexto, 2018a.

COSSON, Rildo. Círculos de leitura e letramento literário. 1. ed., 2 impressão. São Paulo: Contexto, 2018b.

COSSON, Rildo. O espaço da literatura na sala de aula. In: PAIVA, Aparecida, MACIEL, Francisca, COSSON. Rildo. (Coord.). Literatura: ensino fundamental. Brasília: Ministério da Educação, Secretaria de Educação Básica, 2010. (Coleção Explorando o Ensino; v. 20).

DALVI, M. A. Literatura na escola: propostas didático-metodológicas. In: DALVI, M. A.; REZENDE, N. L.; JOVER-FALEIROS, R. (Orgs). Leitura de literatura na escola. São Paulo: Parábola Editorial, 2013.

DANIEL, HARVEY. Literature circles. Voice and choice in Books Clubs and Reading Groups. 2 ed. Portland, Maine: Stenhouse Publishers, 2002.

GAGETE, Lourdes Carolina. O Gralha, menino de rua. 1. ed. São Pulo: Paulus, 2008.

KRESS, G. Literacy in the New Media. London: Routledge, 2003.

KRESS; VAN LEEUWEN, T. Reading images: the grammar of visual design. London, New York: Routledge [1996], 2006.

LAGO, Ângela. Cenas de Rua. Belo Horizonte: RHJ, 1994. Disponível em http://blogeditorarhj. blogspot.com/2010/06/livro-de-imagem-cena-de-rua-de-angela.html. Acesso em: 10 de maio de 2019.

LAJOLO, Marisa. Do mundo da leitura para a leitura do mundo. 6. ed. São Paulo: Ática, 2000. 
MACHADO, Anna Rachel. Diário de leituras: a construção de diferentes diálogos em sala de aula. In: Linha d'Água, v. 18, no 1. São Paulo: Companhia das Letras, 2005. p. 61-80.

ROJO, R. Pedagogia dos multiletramentos. In: ROJO, R. \& MOURA, E. (orgs.) Multiletramentos na escola. São Paulo: Parábola, 2012.

ROJO, R. Letramentos múltiplos, escola e inclusão social. São Paulo: Parábola Editorial, 2009.

ROUXEL, Annie. Aspectos metodológicos do ensino da literatura. Tradução de Neide Luzia de Rezende. In: DALVI, Maria Amélia, REZENDE, Neide Luzia de; JOVERFALEIROS, Rita (orgs.). Leitura de literatura na escola. São Paulo: Parábola, 2013.

SOARES, Magda Becker. A escolarização da literatura infantil e juvenil. In: EVANGELISTA, Aracy et al. (Org.). A escolarização da leitura literária: o jogo do livro infantil e juvenil. 2. ed. Belo Horizonte: Autêntica, 2006. p. 17-48.

SILVA, Ivanda Maria Martins. Literatura em sala de aula: da teoria literária à prática escolar. ANAIS DO EVENTO PG LETRAS 30 Anos, 2003, vol. I (1): 514-527.

THIOLLENT, Michel. Metodologia da pesquisa-ação. 7. ed. São Paulo: Cortez, 1996.

VIEIRA, Josenia. Globalização, tecnologias e linguagens. In: VIEIRA, J; SILVESTRE, C (orgs) Introdução à Multimodalidade: Contribuições da Gramática Sistêmico-Funcional, Análise de Discurso Crítica e Semiótica Social. Brasília, DF:J. Antunes Vieira, 2015, p. 14-43. 